Article

\title{
Length of Operational Life and Its Impact on Life-Cycle Costs of a Tractor in Switzerland
}

\author{
Markus Lips \\ Agroscope, Tänikon, CH-8356 Ettenhausen, Switzerland; markus.lips@agroscope.admin.ch;
} Tel.: +41-58-480-31-85

Received: 22 June 2017; Accepted: 2 August 2017; Published: 8 August 2017

\begin{abstract}
Assuming full exhaustion of their estimated service life-also referred to as estimated technical working life- the low annual utilisation of agricultural machines in Switzerland leads to a long operational life. To determine the costs of an additional year's service, we calculate the life-cycle costs (LCCs), which encompass all costs for an $82 \mathrm{~kW}$ four-wheel-drive tractor over its entire operational life. Assuming full utilisation of the estimated service life of 10,000 $\mathrm{h}$, five operating versions are compared, each with an operational life of between 10 and 30 years and matched annual utilisations between $1000 \mathrm{~h}$ and $333 \mathrm{~h}$. A key finding is that an additional year in service increases LCCs by $4.5 \%$ of the tractor's purchase price. In addition, we carry out a sensitivity analysis by applying discount rates of between $0 \%$ and $4 \%$, finding that a comparatively high discount rate of 3\% leads to almost identical LCCs for all operating versions. We conclude that the annual utilisation and the resulting duration of operational life have a strong impact on LCCs. A short operational life associated with high annual utilisation is a promising strategy for substantially cutting machinery costs.
\end{abstract}

Keywords: life-cycle costing; total cost of ownership; operational lifespan; machine; agriculture

\section{Introduction}

A farm survey of agricultural machines in Switzerland brought to light that the degree of utilisation is generally low [1]. For instance, 529 four-wheel-drive tractors had an average annual utilisation of $313 \mathrm{~h}$. Given an estimated service life-also referred to as estimated technical working life-for tractors of 10,000 h [2], a tractor must be in service for 32 years. Accordingly, most tractors must be financed and maintained for several decades. In view of rigorous international competition, the question arises as to what impact the duration of operational life-also variously called mechanical life, length of service, or period of use-has on the machinery costs. Specifically, we are interested in the costs of an additional year in service. To obtain these, an overall or life-cycle cost (LCC) analysis is required, which encompasses all costs arising from owning, operating, maintaining, and ultimately disposing of a project [3].

According to the typology of life-cycle costing presented by Lichtenvort et al. [4], a conventional LCC analysis focuses on real, internal costs from the perspective of one market actor, and is also referred to as financial life-cycle costing [5]. In addition to a conventional LCC, an environmental LCC analysis also includes external costs, followed by the societal LCC covering all costs by anyone in society, which also includes the environmental LCC [4]. As pointed out by Saccani et al. [6], life-cycle costing adopts the product perspective, whilst the total cost of ownership (TCO) assumes the purchaser's-in our case, the farmer's-standpoint. By contrast, conventional life-cycle costing does not take account of transaction costs, or does so only to a limited degree [7].

Several analyses of the LCCs of tractors can be found in the literature. According to Lichtenvort et al. [4], the General Accounting Office in the US applied LCCs for tractors as early 
as 1933. Jekayinfa et al. [8] analyse the replacement policy for three tractor types in Nigeria by means of LCC. Assuming an identical annual utilisation, the authors report both the accumulated total costs and the average total costs per year over a 12-year period. Whereas the average total costs per year decrease in the beginning, they start to rise again between the eighth and ninth year, which, according to the authors, represents the standard rule for replacement. Mousazadeh et al. [9] derive the LCC for a conventional tractor including an internal combustion engine and a solar assist plug-in hybrid electric tractor. The external costs of $\mathrm{CO}_{2}$ equivalent are taken into account by carrying out an environmental LCC analysis. Assuming a similar engine power for both tractors and a comparison period of 25 years, the environmental LCCs of the conventional tractor amount to 1.7 times those of the electric tractor.

As far as we are aware, the length of operational life and its effect LCC has never been addressed in the literature, in connection with machines in agriculture or elsewhere. This paper aims to fill this gap by calculating the LCC for one particular tractor type. Under the assumption of full utilisation of the estimated service life, five operating versions with different lengths of operational life are compared.

This paper is organised as follows: Section 2 outlines the method applied and presents the data used. The results and discussion are presented in Sections 3 and 4, respectively. The paper ends with the conclusions.

\section{Method}

\subsection{Conventional LCCs Analysis}

For the analysis, we focused on an average-sized tractor for current investment and selected from [2] the four-wheel-drive model with an engine of 82 kilowatts (kW; corresponds to 111.5 horsepower). As mentioned above, we assumed an estimated service life of 10,000 h [2], which constitutes the functional unit. Because the qualifications and experience of the tractor drivers may vary substantially, the costs of driving the tractor were not taken into consideration. In order to focus on the impact of the duration of its operational life, we assumed that there are neither costs nor benefits at the end of the tractor's life. Consequently, the potential costs for disposing of the tractor, salvage value after the estimated service life, and the value of its components (e.g., iron as a raw material) were omitted. In addition, because transaction costs were not considered crucial to our analysis, we assumed them to be zero. Accordingly, there were neither costs related to the acquisition of the tractor (e.g., working hours for comparing prices of different tractor makes) nor positive effects such as a discount on the purchase price due to bargaining. To summarise, we conducted a conventional LCC analysis for the farmer as a tractor owner. Furthermore, the situation here is similar to that of machine construction, where LCC often equals TCO because transaction costs are of minor importance compared to the purchase price and operating costs [7].

\subsection{Five Operating Versions}

In order to assess the impact of the length of the operational life on LCCs, we distinguished five operating versions with different operational lifespans. The length of operational life is denoted as $n$ and lasts 10 (operating version 1), 15 (2), 20 (3), 25 (4), and 30 years (5), respectively. Assuming that the estimated service life of $10,000 \mathrm{~h}$ is fully exhausted in all operating versions, the annual utilisations $(A U)$, measured in hours per year, were calculated as follows:

$$
A U=\frac{10,000 \mathrm{~h}}{n}
$$

Accordingly, the $A U$ amount to 1000 (operating version 1), 667 (2), 500 (3), 400 (4), and $333 \mathrm{~h}$ (5), respectively. 


\subsection{Four Cost Items}

We organised all machinery costs into four cost items, namely capital costs, buildings and fees, fuel, and repair and maintenance costs. Formulating the LCC of the tractor, we applied a formal depiction similar to that of Cuéllar-Franca and Azapagic [10]:

$$
L C C=C_{C}+C_{B F}+C_{F U}+C_{R M}
$$

$C_{C}$ denotes capital costs, while $C_{B F}$ refers to building costs and fees. Both are typically considered as fixed costs. The costs for fuel $\left(C_{F U}\right)$ and repair and maintenance $\left(C_{R M}\right)$ form part of the variable costs. In order to analyse time periods of up to 30 years, it is helpful to depict costs as annually recurring identical payments. Three out of four cost items have identical nominal costs per year. Accordingly, we reformulated Equation (2) by introducing annual costs for capital $\left(A_{C}\right)$, buildings and fees $\left(A_{B F}\right)$, and fuel $\left(A_{F U}\right)$, and multiplying them by the number of years $(n)$ :

$$
L C C=n\left(A_{C}+A_{B F}+A_{F U}\right)+C_{R M}
$$

The repair and maintenance costs $\left(C_{R M}\right)$ were calculated differently, as explained below (see Section 2.7).

Except for the repair and maintenance costs, we used the machinery-cost report produced by the Agroscope research station [2] as a data source. This report is comparable to machinery-cost-planning material supplied to farm managers in other countries or regions such as the United Kingdom [11], South Africa [12], and Minnesota, USA [13]. Methodological descriptions of machinery-cost calculations can be found in [14-16].

\subsection{Capital Costs}

The capital costs included depreciation and interest. The average purchase price $(P P)$ of the tractor in question was 110,000 Swiss Francs (110 kCHF [2]; average exchange rates 2016; $1 \mathrm{CHF}=0.92$ Euro = 1.02 USD; https: / / data.snb.ch, accessed 9 January 2017). PP refers to price lists, and does not take account of a possible discount due to bargaining. We assumed complete debt financing and applied the interest rate $i$ of 2.5\% [2]. The latter reflects an average of different types of loans (e.g., credits, interest-free loan [16]). In order to provide uniform costs per year, we calculated the annuity costs $\left(A_{C}\right)$, also called annual capital recovery costs $(A C R C$ [17]):

$$
A_{C}=P P \frac{i}{1-(1+i)^{-n}}
$$

\subsection{Buildings and Fees}

Costs for buildings comprised the rent for the place where the tractor was garaged (CHF 1066), which equals the product of necessary volume $\left(82 \mathrm{~m}^{3}\right)$ and the rental rate $\left(\mathrm{CHF} 13 / \mathrm{m}^{3}\right)$ for a fire-proof garage [2]. The fees included insurance and number-plate costs (CHF 700; [2]). Together, buildings and fees $\left(A_{B F}\right)$ amounted to CHF 1766 per annum.

\subsection{Fuel}

The per-hour fuel costs (CHF 14.46) are the product of the four factors engine power $(82 \mathrm{~kW})$, specific fuel consumption (0.3 L diesel per $\mathrm{kW}$ ), price per litre of diesel (CHF 1.47), and average engine load factor (0.4) [2]. The latter was derived from Rinaldi et al. [18], who provided the engine-load factors for 49 activities [16]. The hourly costs are multiplied by the $A U$ to obtain annual costs:

$$
A_{F U}=A U * C H F 14.46
$$




\subsection{Repair and Maintenance}

Exceptionally, the repair and maintenance costs are not based on the Agroscope machinery report. Instead, we applied the coefficients derived from the estimation of the annual repair and maintenance costs of four-wheel-drive tractors in Switzerland with reference to power functional form [19]. The repair and maintenance costs of year $j\left(R M C_{j}\right)$ are expressed as a proportion of the purchase price. Besides the annual utilisation in hours $(A U)$ and the ageing effect of the year $j$, the constant $k$ are considered ( $k$ is equal to 0.000439 and refers to the product of the constant and a resulting term for engine power of 111.5 horsepower):

$$
R M C_{j}=k * A U^{0.51} j^{0.28}
$$

The exponent of the $A U(0.51)$ is less than one, indicating that the repair and maintenance costs increase by a disproportionately low amount. For instance, doubling the annual utilisation from 500 to $1000 \mathrm{~h}$ boosts costs by only $42 \%$. Accordingly, there is an economy-of-scale effect. Intuitively, this can be explained by the oil change for the engine and gearbox, which is carried out every year independently of the annual utilisation: the longer the operational life, the more oil changes are necessary, the higher the LCCs. The ageing effect also shows a steady increase with the years, and addresses material fatigue, among other factors.

The repair and maintenance costs from Equation (6) are summed up for all years of the tractor's operational life and multiplied by the purchase price, yielding the accumulated repair and maintenance costs for the full operational life $\left(C_{R M}\right)$ :

$$
C_{R M}=P P * \sum_{j=1}^{n} R M C_{j}=P P * k * A U^{0.51} \sum_{j=1}^{n} j^{0.28}
$$

\subsection{Discounting}

As a quasi-dynamic method [20], conventional LCC analysis deals with costs occurring at different moments in time. For comparison reasons, we converted all costs to the present value $(P V)$ in the first year, the year the tractor was bought. During the entire period of up to 30 years, we had annual payments in current prices for all four cost items. Since prices cannot be predicted over such long time periods, we assumed that they remained constant, and thus did not need to be adjusted for inflation. As we were dealing with long periods of time, we needed to recognise the individual farmer's time value of money for future costs by using discount rates [3]. Davis et al. [21] denoted this effect as opportunity costs for capital. Discounting makes current costs worth more than those occurring in the future [22], referring to the effect that, in the meantime, the money can be used for other purposes. Considering the discount rate $d$ in order to derive the PV of the LCCs, Equation (3) must be modified as follows:

$$
L C C=\frac{(1+d)^{n}-1}{d(1+d)^{n}}\left(A_{C}+A_{B F}+A_{F U}\right)+P P * k * A U^{0.51} \sum_{j=1}^{n} \frac{j^{0.28}}{(1+d)^{j}}
$$

For the annually recurring uniform amounts of capital costs, costs of buildings and fees, and fuel costs, Fuller and Petersen [3] provided the discounting formula for the discount rate. In the case of repair and maintenance costs, annual costs need to be discounted individually.

For the numerical choice of the discount rate $d$, it is important to note that savings interest rates are currently comparatively low, or even negative (e.g., 10-year Swiss government bonds in June 2017: $-0.02 \%$; https: / / data.snb.ch, accessed 26 July 2017). In addition, the return on farming families' invested capital is typically negative in Switzerland (e.g., $-7.2 \%$ for 2015 [23]). Nevertheless, in order to analyse the influence of discounting on results, we carried out a sensitivity analysis by applying rates of $0 \%, 1 \%, 2 \%, 3 \%$, and $4 \%$, respectively. Although discount rates of $2 \%$ and more could be 
considered high compared to actual interest rates, they were at the lower end, or even outside of, the typical range of between $4 \%$ and $15 \%$, as mentioned by Hunkeler et al. [20].

It should be noted that capital cost and the discount rate or opportunity costs are independent of each another. We assumed that the tractor was completely financed by debt capital (see Section 2.4), while opportunity costs refer to the course of business or own capital. Given that three out of the five discount rates used were below the interest rate of $2.5 \%$ (see Section 2.4), it would make sense for the farmer to finance the tractor with their own capital. Given that the average annual salary of a family work force in 2015 of $\mathrm{kCHF} 44.6$ [23] comes to $41 \%$ of the tractor's purchase price, it is unlikely that the farm business provides enough liquidity for complete equity financing.

\subsection{Additional Costs per Year}

Taking operating version 1 as a base, the additional costs per additional year are expressed as a percentage $z$ of the $P P$ :

$$
z=\frac{L C C_{v}-L C C_{10}}{P P(v-10)} 100 \%
$$

The LCCs of operating version 1 (10 years, $L C C_{10}$ ) are subtracted from those of operating version $v\left(L C C_{v}\right.$; e.g., 15 years) and divided by both the $P P$ and the differences in years of the operating version $v$ and 10 years. Finally, multiplication by $100 \%$ yields the percentage value.

\section{Results}

Table 1 reports the LCCs for all cost items, as well as the total costs for all five operating versions with a discount rate of $0 \%$. Looking at the LCCs, we see that extending the operational life leads to substantial additional costs. LCCs are between $\mathrm{kCHF} 313.4$ (operating version 1) and $\mathrm{kCHF} 413.0$ (operating version 5), while an additional five years increases LCCs by around kCHF 25, or $23 \%$ of PP. In other words, halving the operational life (e.g., to 10 years from 20 years) reduces LCCs by at least $14 \%$.

Table 1. Life-cycle costs for five operating versions with a discount rate of $0 \%$ (present value).

\begin{tabular}{ccccccc}
\hline \multirow{2}{*}{ Operating Details and Cost Items } & \multirow{2}{*}{ Unit } & \multicolumn{5}{c}{ Operating Version } \\
\cline { 3 - 7 } & & $\mathbf{1}$ & $\mathbf{2}$ & $\mathbf{3}$ & $\mathbf{4}$ & $\mathbf{5}$ \\
\hline Operational life & years & 10 & 15 & 20 & 25 & 30 \\
Annual utilisation & hours & 1000 & 667 & 500 & 400 & 333 \\
\hline Capital costs & $\mathrm{kCHF}$ & 125.7 & 133.3 & 141.1 & 149.3 & 157.7 \\
Buildings and fees & $\mathrm{kCHF}$ & 17.7 & 26.5 & 35.3 & 44.2 & 53.0 \\
Fuel & $\mathrm{kCHF}$ & 144.6 & 144.6 & 144.6 & 144.6 & 144.6 \\
Repair and maintenance & $\mathrm{kCHF}$ & 25.5 & 34.3 & 42.6 & 50.3 & 57.7 \\
\hline LCCs & $\mathrm{kCHF}$ & 313.4 & 338.7 & 363.6 & 388.3 & 413.0 \\
\hline
\end{tabular}

kCHF $=1000$ Swiss Francs; LCC $=$ life-cycle cost.

The four cost items behave differently. Capital costs are dominated by depreciation $(P P=\mathrm{kCHF} 110)$. The increase in capital costs between versions 5 and 1 amounts to kCHF 32.0, and refers to the additional 20 years for which the capital is committed. Buildings and fees are proportional to operational life. Accordingly, version 5 (30 years) shows three times the costs of version 1 (10 years). The cost for fuel remains constant, while the repair and maintenance costs obtained for version 5 are more than double those for operating version 1.

Results can also be converted to the single work-hour by dividing LCCs by 10,000 h. Thus, a tractor-hour costs CHF 31.34 in operating version 1. As a further result, LCCs clearly exceed the purchase price $P P$. The $L C C / P P$ ratios range from 2.8 (operating version 1 ) to 3.8 (operating version 5 ).

Table 2 reports the PV of LCCs when considering different discount rates. For operating version 1 , an additional 1\% discount rate lowers LCCs by around 5\% (e.g., kCHF 296.7 instead of kCHF 313.4). 
The discount rate strongly influences the course of LCCs across the operating versions. Whereas there is an increase for discount rates of $2 \%$ or less, LCCs remain more or less stable assuming a discount rate of $3 \%$. In the case of $4 \%$, LCCs decrease when the operational life is prolonged.

Table 2. Life-cycle costs for five operating versions assuming different discount rates (present value).

\begin{tabular}{ccccccc}
\hline \multirow{2}{*}{ Discount Rate } & \multirow{2}{*}{ Unit } & \multicolumn{5}{c}{ Operating Version } \\
\cline { 3 - 7 } & & $\mathbf{1}$ & $\mathbf{2}$ & $\mathbf{3}$ & $\mathbf{4}$ & $\mathbf{5}$ \\
\hline \multirow{2}{*}{$0 \%$} & LCCs in kCHF & 313.4 & 338.7 & 363.6 & 388.3 & 413.0 \\
& Add. annual costs $z$ & - & 4.60 & 4.56 & 4.54 & 4.53 \\
\hline \multirow{2}{*}{$1 \%$} & LCCs in kCHF & 296.7 & 312.8 & 327.7 & 341.5 & 354.4 \\
& Add. annual costs $z$ & - & 2.93 & 2.81 & 2.71 & 2.62 \\
\hline \multirow{2}{*}{$2 \%$} & LCCs in kCHF & 281.3 & 289.7 & 296.5 & 302.2 & 306.8 \\
& Add. annual costs $z$ & - & 1.52 & 1.38 & 1.27 & 1.16 \\
\hline \multirow{2}{*}{$3 \%$} & LCCs in kCHF & 267.0 & 268.9 & 269.4 & 269.0 & 267.9 \\
& Add. annual costs $z$ & - & 0.34 & 0.09 & 0.05 & 0.02 \\
\hline \multirow{2}{*}{$4 \%$} & LCCs in kCHF & 253.8 & 250.2 & 245.8 & 240.9 & 235.8 \\
& Add. annual costs $z$ & - & -0.64 & -0.72 & -0.78 & -0.82 \\
\hline
\end{tabular}

$\mathrm{kCHF}=1000$ Swiss Francs; LCC $=$ life-cycle cost. $z$ refers to operating version 1 and is expressed as a percentage of the purchase price $(P P)$.

In addition, Table 2 reports the effect of an additional year on LCCs ( $z$, Equation (9)) in terms of the percentage of purchase price $(P P)$, based on operating version 1 . For example, assuming a discount rate of $0 \%$, extending the operational life by one year means additional LCCs between $4.5 \%$ and $4.6 \%$ of $P P$, while with a discount rate of $3 \%$, the additional costs per year are close to zero.

\section{Discussion}

It is important to bear in mind that interest rates were historically low at the time of this analysis. In the long run, capital costs might be greater, and responsible for a larger percentage of LCCs than that presented here.

The core assumption of this paper (full exhaustion of the estimated service life of 10,000 h) could be questioned. There might be several reasons for earlier replacement, summarised in Key et al. [24], such as new technical developments. If the estimated service life is not exhausted, LCCs would be lower due to lower variable costs, i.e., fuel costs and repair and maintenance costs. Furthermore, a (rather small) salvage value needs to be assumed at the end. At the same time, the resulting costs per tractor-hour would exceed the presented results, since capital costs, as well as building costs and fees, would be greater per hour of use. A related question is whether tractors stay in service for such long periods as up to 30 years. Albisser et al. [1] presents an average age of 33 years for two-wheel-drive tractors. Although this confirms our assumption, the scope and purpose of use might differ from those of the initial situation when the tractor was purchased.

For all operating versions, no costs or benefits are assumed at the end of the tractor's service life. However, it could be argued that after the exhaustion of its estimated service life, a 10-year-old tractor has a higher salvage value than a 30 -year-old one. Such an assumption would favour a short operational life to an even greater extent.

We also assume that the length of the payback period is identical to the operational life. Alternatively, the payback period could be completed within a maximum of 15 years. The effects of this on our results are minor. For operating version 5 , LCCs would be $6 \%$ lower, assuming a discount rate of $0 \%$. For discount rates of $1 \%$ and $2 \%$, the reductions would amount to $4 \%$ and $1 \%$, respectively. For higher discount rates, LCCs of operating version 5 would actually increase, since the payback period occurs when the discounting effect is relatively low. Accordingly, discount rates of $3 \%$ and $4 \%$ show LCC increases of $1 \%$ and $3 \%$, respectively. 
The analysis reveals a substantial savings potential for farmers. For instance, applying a discount rate of $0 \%$ and starting with operating version 5 , which is close to the current annual utilisation in Swiss agriculture for four-wheel-drive tractors [1], a reduction in operational life down to 25 years, implying an increase in annual utilisation from 333 to $400 \mathrm{~h}$, leads to a reduction in LCCs of kCHF 24.7. This corresponds to more than half $(55 \%)$ of the average annual work income of a full-time family work force in Swiss agriculture in 2015 (kCHF 44.6 [23]).

Assuming that the effects identified are also valid for other agricultural machines, the results presented here help to explain the difference in machinery costs for cropping enterprises [25]. Differentiating between farm enterprises on the basis of the realised hourly remuneration of labour as a performance indicator, the substantial differences in machinery costs between the best- and worst-performing quarter (e.g., CHF 428 for bread cereals per hectare) can stem from different operating conditions, including annual utilisation.

\section{Conclusions}

This paper analyses the impact of length of operational life on the life-cycle costs (LCCs) of an $82 \mathrm{~kW}$ four-wheel-drive tractor, assuming full exhaustion of its estimated service life of 10,000 h. Although some assumptions of the analysis can be called into question, they do not cast doubt on the core result of the analysis-namely, that prolonging the operational life by decreasing the annual utilisation simultaneously brings about a substantial increase in LCCs. Compared to a 10-year operational life as a base case, every additional year of service costs around $4.5 \%$ of the purchase price of the tractor. Increasing the operational life by 10 years corresponds to additional LCCs, amounting to more than the annual salary of a family work force in the Swiss farming sector (kCHF 44.6 [23]).

Given an average annual utilisation of around $300 \mathrm{~h}$ for four-wheel-drive tractors [1] with a theoretical operational life of over 30 years, Swiss farmers could make substantial savings by increasing the annual utilisation. Based on the effects found, we recommend highlighting the importance of the operational life for life-cycle costs in farm-management planning material. Machinery cooperatives allowing the joint use of tractors by several farmers in order to increase the annual utilisation represent a promising strategy for cutting costs. In addition, increased machine utilisation would allow earlier replacement and implementation of technological advances.

The impact of operational life on LCCs can be reduced or even offset by the discount rate referring completely to opportunity costs. The sensitivity analysis shows that with a comparatively high discount rate for capital opportunity costs of $3 \%$, the LCCs are almost independent of operational life.

To our knowledge, the influence of operational life on LCCs has never been addressed in the literature-an astonishing fact when one considers the not inconsequential effects discovered in this study. One reason for this omission might be the scarcity of repair-and-maintenance-cost estimates taking into account both the age and annual utilisation of a tractor, as used in this analysis. However, given the importance of LCCs for (farm) management, we expect the influence of the duration of operational life on LCCs to receive more attention in management research in the future.

Acknowledgments: The authors wish to thank Alexander Zorn, Daniel Hoop, and two anonymous reviewers for their very helpful comments.

Conflicts of Interest: The authors declare no conflict of interest.

\section{References}

1. Albisser, G.; Gazzarin, C.; Gärtner, D. Maschinenkosten in der Praxis: Auslastung, Nutzungsdauer und Reparaturkosten ausgewählter Landmaschinen auf Schweizer Betrieben (In German: Machinery Cost in Practice: Annual Utilisation, Operational Life and Repair Costs for Selected Agricultural Machines from SWISS Farms); ART-Bericht No. 711; Agroscope Reckenholz-Tänikon Research Station: Tänikon, Switzerland, 2009.

2. Gazzarin, C. Maschinenkosten 2016 (In German: Machinery Cost Report 2016); Agroscope Transfer Nr. 142/2016; Agroscope: Tänikon, Switzerland, 2016. 
3. Fuller, S.K.; Petersen, S.R. Life-Cycle Costing Manual for the Federal Energy Management Program, National Institute of Standards and Technology (NIST) Handbook 135, 1995 ed.; National Institute of Standards and Technology (NIST): Gaithersburg, MD, USA, 1996.

4. Lichtenvort, K.; Rebitzer, G.; Huppes, G.; Ciroth, A.; Seuring, S.; Schmidt, W.-P.; Günther, E.; Hoppe, H.; Swarr, T.; Hunkeler, D. Introduction history of life cycle costing, its categorization, and its basic framework. In Environmental Life Cycle Costing; Hunkeler, D., Lichtenvort, K., Rebitzer, G., Eds.; SETAC: Pensacola, FL, USA; CRC Press: Boca Raton, FL, USA, 2008.

5. Hoogmartens, R.; Van Passel, S.; Van Acker, K.; Dubois, M. Bridging the gap between LCA, LCC and CBA as sustainability assessment tools. Environ. Impact Assess. Rev. 2014, 48, 27-33. [CrossRef]

6. Saccani, N.; Perona, M.; Bacchetti, A. The total cost of ownership of durable consumer goods: A conceptual model and an empirical application. Int. J. Prod. Econ. 2017, 183, 1-13. [CrossRef]

7. Geissdörfer, K.; Gleich, R.; Wald, A. Standardisierungspotentiale lebenszyklusbasierter Modelle des strategischen Kostenmanagements (In German: Potentials of standardizing life cycle cost analysis models for strategic cost management). Z. Betr. 2009, 79, 693-716. [CrossRef]

8. Jekayinfa, S.O.; Adebiyi, K.A.; Waheed, M.A.; Owolabi, O.O. Appraisal of farm tractor maintenance practices and costs in Nigeria. J. Qual. Maint. Eng. 2005, 11, 152-168. [CrossRef]

9. Mousazadeh, H.; Keyhani, A.; Javadi, A.; Mobli, H.; Abrinia, K.; Sharifi, A. Life-cycle assessment of a Solar Assist Plug-in Hybrid electric Tractor (SAPHT) in comparison with a conventional tractor. Energy Convers. Manag. 2011, 52, 1700-1710. [CrossRef]

10. Cuéllar-Franca, R.M.; Azapagic, A. Life cycle cost analysis of the UK housing stock. Int. J. Life Cycle Assess. 2014, 19, 174-193. [CrossRef]

11. Craig, K. The Farm Management Handbook 2016/17, The UK Reference for Farm Business Management, 37th ed.; SAC Consulting: Midlothian, VA, USA, 2016. Available online: https://www.sruc.ac.uk/fmh (accessed on 25 July 2017).

12. Lubbe, P.A.; Archer, C.G. Guide to Machinery Costs 2014/2015, Department of Agriculture, Forestry and Fisheries, Pretoria, 2014. Available online: http:/ / www.daff.gov.za/Daffweb3/Portals/0/Statistics\%20and\% 20Economic \%20Analysis/Economic\%20Analysis/Guide\%20to\%20machinery\%20costs\%202014-15.pdf (accessed on 25 July 2017).

13. Lazarus, W.F. Machinery Cost Estimates, University of Minnesota Extension. 2015. Available online: http:/ / www3.extension.umn.edu/sites/default/files/download/Machinery\%20Cost\%20Estimates \% 20June\%202015.pdf (accessed on 25 July 2017).

14. American Society of Agricultural and Biological Engineers (ASABE). Agricultural Machinery Management Data; ASAE D497.7 MAR2011 (R2015); ASABE: St. Joseph, MO, USA, 2015.

15. American Society of Agricultural and Biological Engineers (ASABE). Agricultural Machinery Management; ASAE EP496.3 FEB2006 (R2015) Cor.1; ASABE: St. Joseph, MO, USA, 2017.

16. Gazzarin, C.; Lips, M. Berechnung und Grunddaten der Maschinenkosten (In German: Calculation and Data of Machinery Cost), Online-Bericht; Agroscope Reckenholz-Tänikon Research Station: Tänikon, Switzerland, 2013.

17. Olson, K. Economics of Farm Management in a Global Setting; Wiley: Hoboken, NJ, USA, 2011.

18. Rinaldi, M.; Erzinger, S.; Stark, R. Treibstoffverbrauch und Emissionen von Traktoren Bei Landwirtschaftlichen Arbeiten (In German: Fuel Consumption and Emissions of Tractors in Agricultural Work); FAT-Schriftenreihe Nr. 65; Agroscope Reckenholz-Tänikon Research Station: Tänikon, Switzerland, 2005.

19. Lips, M.; Burose, F. Repair and maintenance costs for agricultural machines. Int. J. Agric. Manag. 2012, 1, $40-46$.

20. Hunkeler, D.; Lichtenvort, K.; Rebitzer, G. Conclusions. In Environmental Life Cycle Costing; Hunkeler, D., Lichtenvort, K., Rebitzer, G., Eds.; SETAC: Pensacola, FL, USA; CRC Press: Boca Raton, FL, USA, 2008.

21. Davis, M.; Coony, R.; Gould, S.; Daly, A. Guidelines for Life Cycle Cost Analysis; Stanford University Land and Buildings: Stanford, CA, USA, 2005.

22. Torgerson, D.J.; Raftery, J. Economic notes: Discounting. Br. Med. J. 1999, 319, 914-915. [CrossRef]

23. Dux, D.; Schmid, D.; Jan, P.; Hoop, D.; Renner, S. Die Wirtschaftliche Entwicklung der Schweizerischen Landwirtschaft 2015, Hauptbericht Nr. 39 der Zentralen Auswertung von Buchhaltungsdaten Stichprobe Einkommenssituation, (In German: The Economic Development of Swiss Agriculture 2015: Main Report No. 39 of the Swiss FADN); Agroscope Transfer Nr. 143/2016; Agroscope: Tänikon, Switzerland, 2016. 
24. Key, R.D.; Edwards, W.M.; Duffy, P.A. Farm Management, 7th ed.; McGraw-Hill: New York, NY, USA, 2012.

25. Hoop, D.; Lips, M.; Zorn, A.; Gazzarin, C. Total production costs at enterprise level. In Proceedings of the 7th International Conference on Agricultural Statistics, Rome, Italy, 26-28 October 2016.

(c)

(C) 2017 by the author. Licensee MDPI, Basel, Switzerland. This article is an open access article distributed under the terms and conditions of the Creative Commons Attribution (CC BY) license (http:/ / creativecommons.org/licenses/by/4.0/). 